\title{
Enzyme transfer from pancreas to plasma during acute pancreatitis. The contribution of ascitic fluid and lymphatic drainage of the pancreas
}

\author{
A D MAYER, M AIREY, JAHAN HODGSON, AND M J McMAHON \\ From the University Department of Surgery, General Infirmary, Leeds
}

SUMmARY Acute pancreatitis was induced in anaesthetised dogs in order to investigate the relative contribution of peritoneal ascitic fluid and thoracic duct lymph as routes of transfer of pancreatic enzymes from the inflamed gland to the blood. In eight animals the exudate from the gland was collected in a plastic bag and continuously drained away, and in a further eight it was allowed to accumulate within the peritoneal cavity. The thoracic duct was cannulated and in four of the animals of each group the lymph which drained was discarded; in the other four it was returned via a venous cannula. The initial rise of plasma amylase and lipase was probably because of the direct transfer of enzyme into veins draining the pancreas or peri-pancreatic tissues. Thereafter transfer of enzyme via the thoracic duct significantly influenced plasma concentrations of amylase and lipase. The majority of enzyme released from the gland accumulated within the peritoneal ascitic fluid, but this intraperitoneal accumulation did not appear to have a significant influence upon lymph or plasma concentrations of amylase or lipase.

Rapid rises in the plasma concentration of pancreatic enzymes are a characteristic and, in consequence, usual diagnostic feature of acute pancreatitis. The level to which plasma enzymes can rise is probably determined by the enzyme producing capacity of the gland and may be more closely related to the aetiology of the pancreatitis than to its severity. Thus attacks of pancreatitis associated with the migration of a gall stone along the biliary tract generally exhibit higher peak plasma concentrations of amylase and lipase than those associated with alcohol. ${ }^{12}$ This is probably because acute gall stone pancreatitis usually develops in a previously normal gland whereas the pancreas is often chronically damaged in patients with acute pancreatitis associated with alcohol abuse.

Patients with severe acute pancreatitis frequently exhibit evidence of multisystem failure, which has been attributed to the presence of active pancreatic enzymes in the plasma or to toxic products which result from enzymic activity in the pancreas, the peripancreatic tissues or in ascitic fluid. Recent

Address for correspondence: Mr M J McMahon, FRCS. University Department of Surgery. The General Infirmary. Leeds LS1 3EX.

Received for publication 1 November 1984 studies have shown that activated proteolytic enzymes form complexes with antiproteases within the intraperitoneal ascitic fluid ${ }^{3}$ and that this fluid has toxic effects both in vivo and in vitro. ${ }^{4}$ Plasma concentrations of $\alpha_{2}$-macroglobulin, the principal antiprotease in plasma, are rarely severely depleted even in the most severe forms of acute pancreatitis ${ }^{6}$ and the majority of $\alpha_{2}$-macroglobulin is free to inhibit proteolysis. ${ }^{7}$ By contrast, antiproteases have limited access to the peritoneal cavity and it has been suggested that proteolytic activity within the peritoneal cavity may result in the formation of toxic products of the hydrolysis of proteins. Antiprotease therapy for patients with acute pancreatitis has been delivered principally by the intravenous route. ${ }^{8-13}$ If the peritoneal cavity is the principal source of the toxic component which underlies the systemic response to severe acute pancreatitis then intravenous therapy may be misdirected, and intraperitoneal therapy more appropriate.

Increases in the plasma concentrations of amylase and lipase occur very rapidly after the induction of acute pancreatitis in experimental animals. This finding, combined with the observation that enzyme concentrations in peripheral venous blood, portal venous blood and thoracic duct lymph were of 
similar magnitude during the first hour of experimental acute pancreatitis, led to the suggestion that the principal determinant of plasma enzyme concentrations during acute pancreatitis was direct venous absorption of enzymes from the inflamed gland. ${ }^{14}{ }^{15}$ From a series of experiments carried out in dogs in which experimental pancreatitis was induced, Egdahl concluded that although the initial rise in plasma enzyme concentration may have been due to direct enzyme transfer into the portal venous blood, the dominant route later in the course of the attack was via the thoracic duct lymph and he suggested that this was because of transperitoneal absorption of enzyme-rich fluid into peritoneal lymphatics. ${ }^{16}$ Subsequently, Waterman and Walsky $^{17}$ found that the raised plasma amylase observed 24 hours after induction of experimental pancreatitis in guinea pigs, could be prevented by enclosing the pancreas in a drained latex tube, thus isolating the gland from the peritoneal cavity. They concluded that transperitoneal absorption was the principal determinant of the serum amylase concentration. Many of the attachments of the pancreas, however, which may have included most of the lymphatics draining the gland, were divided during the experimental preparation. In view of these conflicting data we have carried out further experiments designed to investigate the relative importance of transperitoneal absorption from the ascitic fluid, and direct absorption into pancreatic veins and lymphatics, in dogs with experimental acute pancreatitis. Although serine proteases and phospholipase $A_{2}$ may be the most important enzymes in the pathogenesis of acute pancreatitis, amylase and lipase were studied as markers of enzyme transfer because specific inhibitors of these enzymes are not present and routine bioassay techniques were therefore applicable.

\section{Methods}

DogS

Sixteen mongrel dogs weighing between 16 and 26 $\mathrm{kg}$ were studied. Anaesthesia was induced using intravenous sodium pentabarbitone $(30 \mathrm{mg} / \mathrm{kg})$ and maintained with a halothane/nitrous oxide/oxygen mixture administered through an endotracheal tube. All animals were given an intravenous infusion of physiological saline at a rate of $30 \mathrm{ml}$ per hour. Arterial blood pressure was monitored continuously throughout the experiment via a cannula in the femoral artery. A cannula was inserted into the innominate vein in order to obtain peripheral venous blood samples, and a silicone catheter (Nutricath, Vygon BP, Ecouen, France; $0.8 \mathrm{~mm}$ ID) was inserted into the abdominal trunk of the thoracic duct which was occluded around the catheter using a silk ligature. Lymph was allowed to drain freely through this catheter and was collected over ice. The lymph volume was recorded every 30 minutes, and in eight dogs, a $2 \mathrm{ml}$ sample of lymph was retained for enzyme assay, the remainder of the 30 minute lymph collection being returned via the venous cannula. In the other eight animals, all the drained lymph was retained. All samples of blood and lymph were replaced with equal volumes of a plasma expander containing $35 \mathrm{~g} / \mathrm{l}$ polygeline (molecular weight 35000 ) (Hemacell, Hoechst UK, Hounslow).

In eight animals (four in which lymph was returned and four in which lymph was drained) the pancreatic exudate was drained without the opportunity for contact with the peritoneal cavity. This was achieved by suturing a polyethylene bag around the margins of the pancreas, the sutures being placed where possible in the wall of the stomach and duodenum, care being taken not to damage the pancreas itself. A sump drain was placed into the polyethylene bag and was aspirated continuously, the exudate being collected over ice. The volume that accumulated over each 30 minute period was measured, and retained for enzyme assay. In the other eight animals, a polyethylene bag was also sutured around the gland (as a sham procedure) and was then removed in order to allow the pancreatic exudate to pool within the peritoneal cavity as ascitic fluid. Acute pancreatitis was induced by infusing $10 \mathrm{ml}$ of a $10 \%$ solution of sodium taurocholate containing $1 \mu \mathrm{g}$ per $\mathrm{ml}$ of enterokinase into a cannula secured by a ligature within the main pancreatic duct. The abdomen was closed by suture after induction of pancreatitis.

Blood and lymph samples were collected immediately before and immediately after induction of acute pancreatitis and then at 30 minute intervals for six hours. The abdomen was then reopened and the pancreas examined for evidence of acute pancreatitis and pancreatic necrosis. Free ascitic fluid was collected by suction drainage and swabbing with dry gauze, increase in weight being used to measure the amount of absorbed fluid. The animals were then killed.

All samples of plasma, lymph, pancreatic exudate and free ascitic fluid were preserved at $-70^{\circ} \mathrm{C}$ before enzyme assay. Amylase was assayed by a chromogenic technique (Phadabas, Pharmacia Diagnostics AB, Uppsala, Sweden), and lipase by a turbidometric technique (Lipase UV-system 10, Boeringer Diagnostica, Mannheim, West Germany).

Wilcoxon's rank sum test was used to test for statistical significance. 


\section{Results}

In each animal, acute haemorrhagic pancreatitis and focal pancreatic necrosis were noted on reopening the abdomen at the conclusion of the experiment but hypotension (systolic blood pressure $<100 \mathrm{~mm}$ $\mathrm{Hg}$ ) was not observed during the six hour period of the study nor did any of the animals die during this time.

The plasma concentrations of amylase (Fig. 1) and lipase (Fig. 2) were not reduced by drainage of the pancreatic exudate during the course of the experiment. By contrast, when the thoracic duct lymph was removed from the animal there were significantly lower plasma concentrations of both plasma amylase (Fig. 3) and lipase (Fig. 4) than when the lymph was returned to the venous system. Within 30 minutes of the start of the intraductal infusion of the taurocholate and enterokinase solution, plasma concentrations showed a rapid and statistically significant rise above the baseline concentration $(\mathrm{p}<0.01)$ which was not influenced by drainage of the thoracic duct lymph.

The Table shows the total amounts of fluid, lipase and amylase which accumulated in the pancreatic exudate, thoracic duct lymph and ascitic fluid during the six hours of the experiment, in the dogs in which the pancreatic exudate was drained and those in which the exudate was allowed to pool in the peritoneal cavity. The small amounts of both amylase and lipase in the ascitic fluid from the animals with pancreatic drainage confirmed the efficiency of the bag in preventing leakage of exudate into the peritoneal cavity. The volume of exudate drained from the gland was very similar to the volume of ascitic fluid which was recovered from the animals

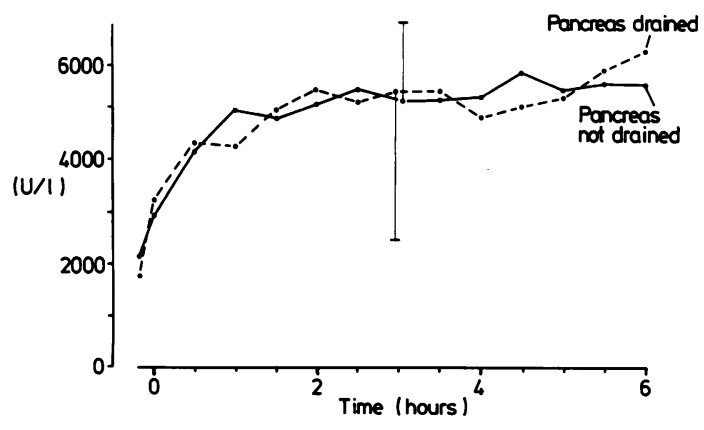

Fig. 1 Influence of pancreatic drainage upon the plasma amylase concentration. Data points indicate the median for the group with representative upper and lower quartiles. $n=$ 8 for each group.

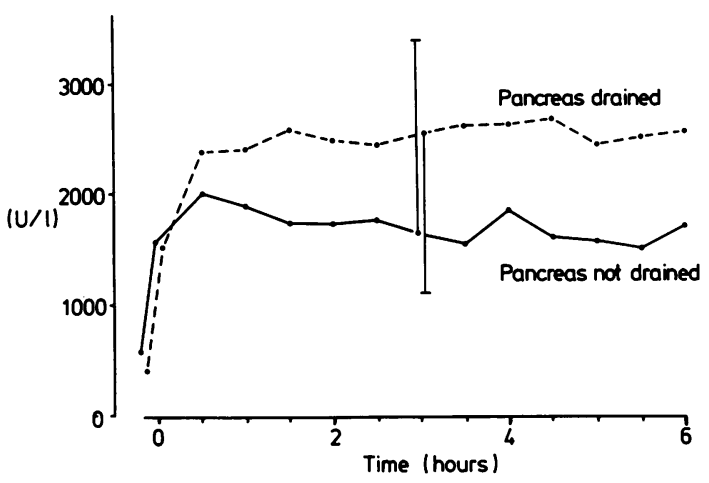

Fig. 2 Influence of pancreatic drainage upon the plasma lipase concentration. Data points indicate the median for the group with representative upper and lower quartiles. $n=8$ for each group.

which did not have pancreatic drainage and the total amount of enzyme (amylase or lipase) recovered from the exudate was also similar to that recovered from the ascitic fluid. In both groups of animals, the enzyme accumulation in the exudate of the drained dogs, and in the ascitic fluid of those which were not drained was much greater than the total transfer of enzyme via thoracic duct lymph (Figs. 5 and 6). Drainage of the pancreatic exudate did not reduce the amount of amylase or lipase in the thoracic duct lymph.

\section{Discussion}

Plasma levels of both amylase and lipase climbed rapidly during and immediately after induction of

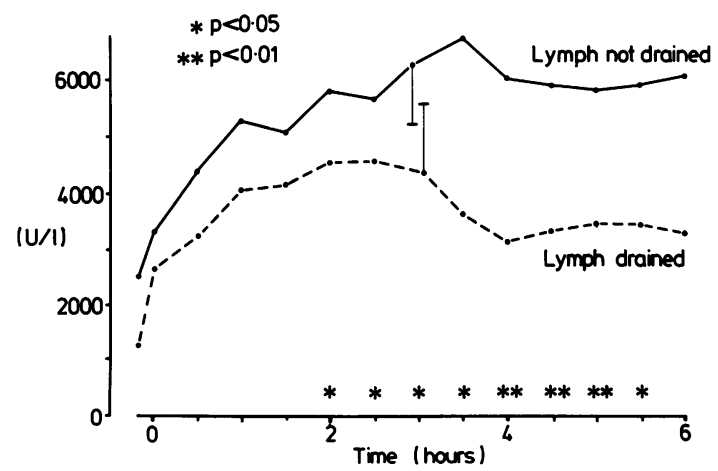

Fig. 3 Influence of thoracic duct drainage upon the plasma amylase concentration. Data points indicate the median for the group with representative upper and lower quartiles. Significance levels are indicated. $n=8$ for each group. 


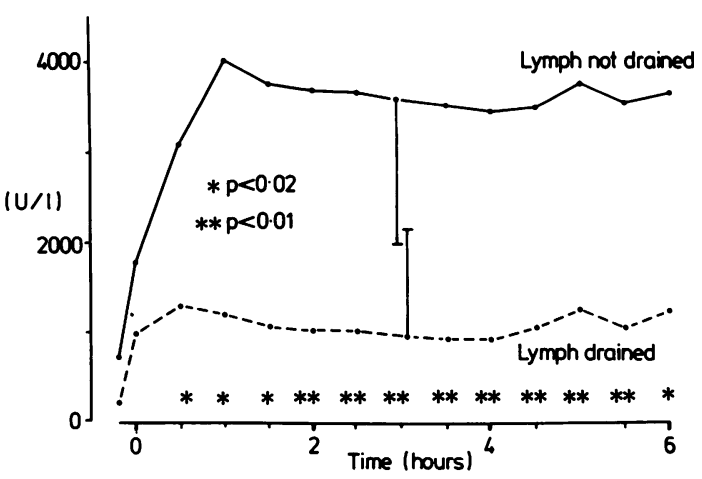

Fig. 4 Influence of thoracic duct drainage upon the plasma lipase concentration. Data points show the median for each group and representative upper and lower quartiles. Significance levels are indicated. $n=8$ for each group.

acute pancreatitis. The rapidity of the rise, and the fact that it was not prevented by draining the thoracic duct lymph, suggest that direct passage of enzymes into veins draining the pancreas was the most likely route of transfer of the enzymes during the initial stages of the experiment. After the first hour, enzyme levels in the plasma tended to reach a plateau, the height of which was significantly less when thoracic duct lymph was prevented from reaching the circulation. This suggests that transfer of enzyme via lymphatic channels which enter the thoracic duct is an important determinant of plasma concentration. In this respect our findings were in agreement with those of Egdahl, ${ }^{16}$ but our data do not support the concept that it is the peritoneal fluid which is the source of the enzyme in the thoracic duct lymph.

It was not possible to comment upon the actual amount of enzyme entering the plasma, but the relatively modest accumulation in the lymph suggests that the total quantity of enzyme which

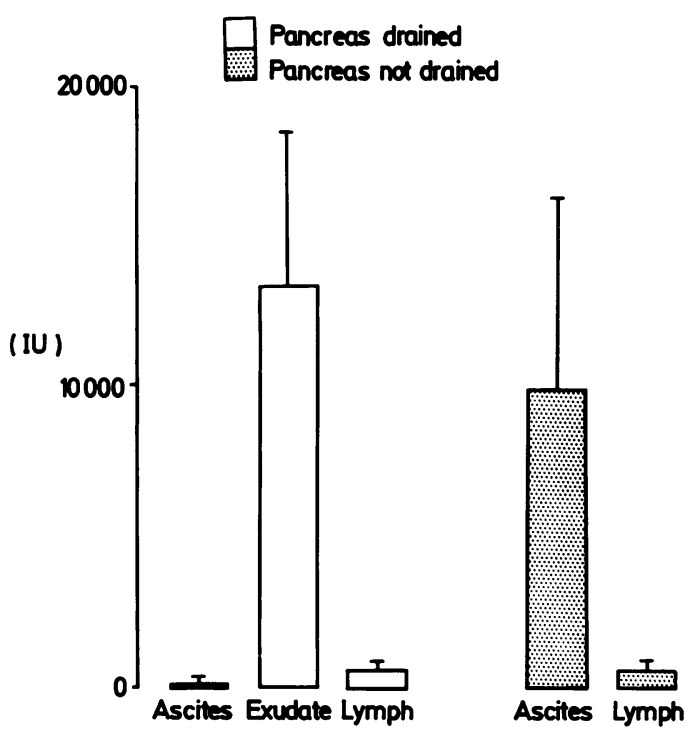

Fig. 5 Amylase accumulation in ascitic fluid, pancreatic exudate and thoracic duct lymph during six hours of acute pancreatitis. The histogram represents the median for each group and the error bar the upper quartile. $n=8$ for each group.

accumulated in the peritoneal cavity far exceeded that which gained access to the plasma. Moreover, the total amount of amylase or lipase measured in the drained pancreatic exudate was similar to that which remained at six hours in the ascitic fluid of animals without pancreatic drainage. This implies that the majority of amylase and lipase which entered the peritoneal cavity was neither destroyed nor transferred to the blood during the initial stages of acute pancreatitis. We must conclude therefore that the lymphatics draining the pancreas and peripancreatic tissues are the principal source of enzyme entering the thoracic duct.

Table Accumulation of fluid, amylase and lipase in peritoneal exudate, ascitic fluid and lymph after the induction of acute pancreatitis. Data are median total output over the six hour period and the interquartile range

\begin{tabular}{|c|c|c|c|}
\hline & Thoracic duct lymph & Pancreatic exudate & Ascitic fluid \\
\hline \multicolumn{4}{|l|}{$\begin{array}{l}\text { Exudate drained } \\
(\mathrm{n}=8)\end{array}$} \\
\hline $\begin{array}{l}\text { volume }(\mathrm{ml}) \\
\text { amylase }(\mathrm{IU}) \\
\text { lipase }(\mathrm{U})\end{array}$ & $\begin{array}{c}87(69-135) \\
571(318-972) \\
594(188-888)\end{array}$ & $\begin{array}{c}171(113-223) \\
8410(7368-20733) \\
13240(6169-18495)\end{array}$ & $\begin{array}{l}47(32-66) \\
554(341-1031) \\
151(97-335)\end{array}$ \\
\hline \multicolumn{4}{|c|}{$\begin{array}{l}\text { Exudate not drained } \\
(n=8)\end{array}$} \\
\hline $\begin{array}{l}\text { volume }(\mathrm{ml}) \\
\text { amylase }(\mathrm{IU}) \\
\text { lipase }(\mathrm{U})\end{array}$ & $\begin{array}{c}78(51-174) \\
536(252-862) \\
649(217-886)\end{array}$ & & $\begin{array}{c}177(141-289) \\
11039(3789-17494) \\
99039(3789-1794)\end{array}$ \\
\hline
\end{tabular}




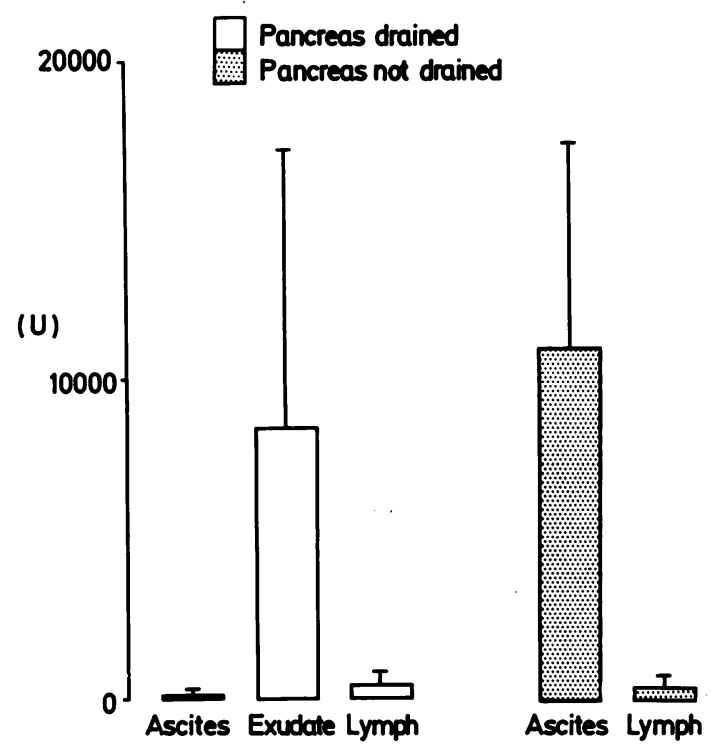

Fig. 6 Lipase accumulation in ascitic fluid, pancreatic exudate and thoracic duct lymph during six hours of acute pancreatitis. The histogram represents the median for each group and the error bar the upper quartile. $n=8$ for each group.

It is possible to cannulate the thoracic duct in man. ${ }^{18}$ Amylase levels in thoracic duct lymph were found to be higher than in simultaneous plasma samples, and normalised during the course of the first week of the attack. ${ }^{19}$ It was suggested that the establishment of a thoracic duct lymphatic fistula conferred therapeutic benefit upon the patients.

Patients with mild pancreatitis caused by gall stones frequently display high concentrations of plasma amylase with little or no free peritoneal fluid. Our data suggest that in these mild attacks of acute pancreatitis, high plasma concentrations of amylase result from direct transfer of enzyme to lymphatic vessels which drain the pancreas, even though the damage suffered by the gland is insufficient to result in significant formation of ascitic fluid. If the pancreas was previously normal, very high concentrations of enzyme collect in the oedema fluid immediately deep to the pancreatic serosa. ${ }^{16}$ Furthermore, in the patient with a severe attack of pancreatitis in whom large volumes of ascitic fluid accumulate, our data would be quite consistent with a relatively modest enzyme response even though high concentrations of amylase and lipase are often present in the ascitic fluid. In addition, if the findings of our study are applicable to patients with acute pancreatitis, removal of intraperitoneal fluid should have little influence upon the plasma concen- trations of enzyme. This indeed was one of the findings of a multicentre study of therapeutic peritoneal lavage which has recently been concluded. $^{20}$

Although our data suggest that little amylase or lipase leaves the peritoneal sump of fluid, there is evidence that large molecular weight proteins such as $\alpha_{2}$-macroglobulin gain access to it. ${ }^{3}$ It is unlikely that intraperitoneal $\alpha_{2}$-macroglobulin originates from sites other than plasma, and it is probable that this protein (molecular weight 725000 daltons) is either a component of the exudate from the inflamed pancreas, or migrates through the peritoneal mesothelium subsequently. The data suggest that the majority of the enzymes released from the inflamed pancreas during acute pancreatitis collect within the peritoneal cavity, although we have only studied amylase and lipase and we cannot be certain that the same fate is shared by pancreatic proteases. By the generation of bioactive peptides, intraperitoneal proteolytic activity may be of importance to the pathogenesis of acute pancreatitis, ${ }^{3}$ and it has been suggested that the biological activity of the ascitic fluid is largely resident within molecules of about 1000 daltons. ${ }^{21}$ Such relatively small molecules might pass more readily into the plasma, either directly into capillaries beneath the peritoneal mesotheliem or into peritoneal lymphatics. Thus while our data suggest that the intraperitoneal ascitic fluid contributes little to enzyme concentrations in the plasma during acute pancreatitis, they do not eliminate the possibility that the intraperitoneal enzyme collection is an important determinant of the systemic response to the attack.

We would like to express out gratitude to The Amélie Waring Foundation, The West Riding Medical Research Trust, The Special Trustees of the General Infirmary at Leeds and Bayer UK Limited, without whose support this study would not have been possible. We are grateful to Carol Nutman for technical assistance and to Mrs Margaret Richardson for the preparation of the manuscript.

\section{References}

1 Paloyan D, Simonowitz D. Diagnostic considerations in acute alcoholic and gallstone pancreatitis. Am J Surg 1976; 132: 327-31.

2 McMahon MJ. Amylase and the diagnosis of pancreatic disease. In: Mitchell CJ, Kelleher J, eds. Pancreatic disease in clinical practice. London: Pitman Books, 1981: 173-92. 
3 Ballidin G, Eddaland A, OhlssonK. Studies on the role of the plasma protease inhibitors on in-vitro C3 activation and in acute pancreatitis. Scand $J$ Gastroenterol 1981; 16: 603-9.

4 Pappas TN, Lessler MA, Ellison EC, Carey LC. Pancreatitis associated ascitic fluid: effect on the oxygen consumption of liver cells. Proc Soc Exp Biol Med 1982; 169: 438-44.

5 Traverso LW, Pullos TG, Frey CF. Hemodynamic characterisation of porcine hemorrhagic pancreatitis ascites fluid. J Surg Res 1983; 34: 254-62.

6 McMahon MJ, Bowen M, Bradley P, et al. Relationship of alpha $\alpha_{2}$-macroglobulin and other antiproteases to the clinical features of acute pancreatitis. Am J Surg 1984; 147: 164-70.

7 Lasson $\AA$. Acute pancreatitis in man. A clinical and biochemical study of pathophysiology and treatment. Scand J Gastroenterol suppl 99: 1984.

8 Trapnell JE, Rigby CC, Talbot CH, Duncan EHL. A controlled trial of Trasylol in the treatment of acute pancreatitis. Br J Surg 1974; 61: 177-82.

9 MRC Working Party. Death from acute pancreatitis. MRC multicentre trial of glucagon and aprotinine. Lancet 1977; 2: 632-5.

10 Imrie CW, Banjamin IS, Ferguson JC et al. A single centre double blind trial of Trasylol therapy in primary acute pancreatitis. Br J Surg 1978; 65: 337-41.

11 Tanaka N, Tsuchiya R, Ishii KW. Comparative clinical study of Foy and Trasylol in acute pancreatitis. $A d v$ Exp Biol Med 1979; 120B: 367-78.

12 Stone $\mathrm{HH}$, Fabian TC. Peritoneal dialysis in the treatment of acute alcoholic pancreatitis. Surg Gynecol Obstet 1980; 150: 878-82.

13 Cuschieri A, Wood RAB, Cumming JRG, Meehan SE, Mackie CR. Treatment of acute pancreatitis with fresh frozen plasma. Br J Surg 1983; 70: 710-2.

14 Popper HL, Necheles H. Pathways of enzymes into blood in acute damage of the pancreas. Proc Soc Exp Biol Med 1940; 43: 220-2.

15 Howard JM, Smith AK, Peters JJ. Acute pancreatitis: pathways of enzymes into the blood stream. Surgery 1949; 26: 161-6.

16 Egdahl RH. Mechanism of blood enzyme changes following production of experimental pancreatitis. Ann Surg 1958; 148: 389-400.

17 Waterman NG, Walsky RS. Tansperitoneal absorption of amylase in acute experimental pancreatitis. Surg Gynecol Obstet 1970; 131: 729-32.

18 Linder E, Blomstrand R. Technique for collection of thoracic duct lymph of man. Proc Soc Exp Biol Med 1958; 97: 653-7.

19 Brzek V, Bartos V. Therapeutic effect of the prolonged thoracic duct lymph fistula in patients with acute pancreatitis. Digestion 1969; 2: 43-50.

20 Mayer AD, McMahon MJ, Corfield AP et al. Therapeutic peritoneal lavage for the treatment of severe acute pancreatitis. Results of a multicentre controlled clinical trial. $N$ Engl J Med 1985; 312: 399-404.

21 Ellison EC, Pappas TN, Johnson JA et al. Demonstration and characterisation of the haemoconcentrating effect of ascitic fluid that accumulates during hemorrhagic pancreatitis. J Surg Res 1981; 30: 241-8.

\title{
Forthcoming Scientific Meetings of the British Society of Gastroenterology
}

\author{
Newcastle-upon-Tyne 18-20 September 1985
}

Lancaster 9-11 April 1986

Cardiff 24-26 September 1986

\section{London 15-18 September 1987}

For details of registration please contact: The Administrative Secretary, British Society of Gastroenterology, Rayne Institute, 5 University Street, London, WC1E 6JJ.

Tel: 01-387-3534 (International 44-1-387-3534). 